\title{
PEMBUATAN GAME EDUKASI SEJARAH KERAJAAN SRIWIJAYA MENGGUNAKAN RPG MAKER MV
}

\author{
Tri Ramdhany', Indraguna BAS ${ }^{2}$, Diki Pahrilah ${ }^{3}$, Rio Andriyat Krisdiawan ${ }^{4}$
}

${ }^{1,2}$ Teknik Informatika, Program Studi Manajemen Informatika, Politeknik \& Stmik LPKIA

${ }^{4}$ Teknik Informatika Fakultas Ilmu Komputer Universitas Kuningan

Email : ${ }^{1}$ tri@1pkia.ac.id, ${ }^{2}$ indra@fellow.lpkia.ac.id, ${ }^{3}$ diki@ fellow.lpkia.ac.id, ${ }^{4}$ rioandriyat@uniku.ac.id,

\begin{abstract}
Abstrak
Game saat ini banyak diminati oleh kalangan anak anak, remaja hingga dewasa dan menjadikan media hiburan. Role Playing Game ( $R P G)$ adalah Pemain game akan terlibat dalam alur cerita yang kompleks sehingga pemain game akan merasa seperti tokoh dalam game tersebut.Game ini dibuat bertujuan untuk media pembelajaran mengal sejarah kerajaan di Indonesia dengan menggunakan RPG Maker MV. Game ini berkisah mengenai sejarah kerajaan sriwijaya dan mengambil salahsatu kisah Raja yang terkenal yaitu Raja Balaputradewa Berita mengenai Raja Balaputradewa awal diketahui dari catatan Prasasi Nalanda. Raja Balaputradewa menjabat sekitar abad ke-9, pada masa kekuasaannya, kerajaan Sriwijaya berkembang cepat menjadi kerajaan besar dan menjadi sebuah pusat agama Buddha di Asia Tenggara.
\end{abstract}

Kata Kunci : Game, RPG, Kerajaan Sriwijaya

\section{Abstract}

Games are currently in great demand by children, teenagers to adults and become entertainment media. Role Playing Game (RPG) is a game player will be involved in a complex storyline so that gamers will feel like a character in the game. This game tells the story of the history of the Sriwijaya Kingdom and takes one of the famous King stories, namely King Balaputradewa. King Balaputradewa served around the 9th century, during his reign, the kingdom of Srivijaya developed rapidly into a large kingdom and became a center of Buddhism in Southeast Asia.

Keywords: Game, RPG, Sriwijaya Kingdom

\section{PENDAHULUAN}

\subsection{Latar Belakang}

Di bidang pendidikan sangatlah penting bagi anak bangsa indonesia untuk menjadi anak bangsa yang cerdas serta berpendidikan pada bidang sejarah yang sangat penting bagi anak Indonesia untuk dipelajari "Oleh karena itu perbaikan atau perubahan pendidikan pada semua tingkat dan bidang terus-menerus dilakukan sebagai upaya untuk kepentingan masa depan bangsa dalam rangka mewujudkan salah satu tujuan nasional Indonesia yaitu mencerdaskan kehidupan bangsa, termasuk dalam perbaikan pembelajaran"(Priyono \& Buditjahjanto, 2012).

Sejarah ini di ambil dari berbagai museum di sumatra dan buku buku sejarah kerajaan sriwijaya. Kerajaan Swriwijaya terletak di Palembang Sumatra selatan dan didirikan kerajaan pada tahun 600 an sampai tahun 1100. "Karena sejarah sriwijaya telah menjadi icon kebesaran Sumatra, dan kerajaan besar nusantara di jawa timur selain majapahit. Pada abad ke 20 kedua kerajaan tersebut menjadi rujukan oleh kaum nasionalis untuk menunjukan 
JURNAL NUANSA INFORMATIKA

Volume 15 Nomor 2, Juli 2021

bahwasanya Indonesia adalah satu kesatuan negara sebelum kolonialisme Belanda"(Wulandari, 2015) dan di ambil dari kisah Raja Balaputradewa Nalanda. Raja Balaputradewa merupakan keturunan dari Dinas Syailendra, yaitu putra dari Raja Samaratungga dengan Dewi Tara dari kerajaan Sriwijaya.

Di zaman modern ini banyak sekali game sejarah kerajaan kerajaan eropa dan jarang membuat game sejarah tentang kerajaan yang ada di indonesia terutama buat anak bangsa indonesia yang bisa melupakan sejarah negaranya sendiri ,maka dibuatkanlah game edukasi Role Playing Game (RPG) sejarah kerajaan sriwijaya untuk di mainkan oleh anak anak bangsa agar sejarah di negri kita sendiri jangan sampai terlupakan. Karena sangat penting ilmu sejarah bagi anak anak bangsa agar mengetahui betapa susah payah mempertahankan pulau pulau di Indonesia dari jajahan colonial negara negara di eropa, memperlihatkan ke setiaan terhadap kerajaan atau negara dan kesetiaan terhadap pemimpin, merelakan mati demi mempertahankan tanah airnya dari jajahan negara lain, budaya budaya yang yang unik dan menarik, dan agama.

\subsection{Rumusan Masalah}

1. Jarang sekali anak anak memainkan game sejarah di negaranya sendri.

2. Game Role Playing Game (RPG) biasanya kebanyakan sejarah kerajaan eropa.

3. Belum tercitptanya game RPG sejarah kerajaan sriwijaya di indoneisa.

\subsection{Tujuan}

1. Agar anak anak Indonesia bisa memainkan game sejarah agar tidak terlupakan.
p-ISSN : 1858-3911, e-ISSN : 2614-5405

https://journal.uniku.ac.id/index.php/ilkom

2. Memperbanyak game edukasi tentang sejarah Indonesia.

3. Agar mengetahui perjuangan orang orang terdahulu.

\subsection{Manfaat}

1. Agar anak anak Indonesia bisa mengetahui sejarah sejarah Indonesia.

2. Mempunyai wawasan yang luas.

3. Agar tidak melupakan sejarah.

\section{Landasan Teori}

\subsection{Sejarah Kerajaan Sriwijaya}

Kerajaan Sriwijaya atau biasa disebut Srivijaya merupakan salah satu kerajaan yang sangat besar, kuat, dan sangat disegani yang berasal dari pulau Sumatera dan sangat memberi pengaruh yang kuat khususnya di bumi Nusantara, dengan daerah kekuasaan yang membentang mulai dari pulau Jawa, Sulawesi, Kalimantan, Thailand, Malaysia atau Semenanjung Malaya, Kamboja, Thailand, bahkan Sumatera Sendiri. Didalam Bahasa Sansekerta, bahwa pengertian sri itu merupakan "Bersinar atau Bercahaya" dan wijaya mempunyai pengertian "Kemenangan".

"Selama berpuluh tahun bahkan beratus tahun lamanya yaitu ketika Kerajaan besar ini runtuh, Kerajaan Sriwijaya mulai terlupakan baik dari kebesarannya dan eksistensinya yang di segani oleh Kerajaan lain maupun dari Kekuatan dan prajuritnya. Baru tahun 1918 Kerajaan Sriwijaya di temukan oleh seorang sejarawan ternama asal Negara Perancis yang bernama George Coedes. Tidak ditemukan tulisan atau catatan lebih lanjut mengenai kebesaran dan kekuatan Kerajaan Sriwijaya dalam historical atau sejarah Indonesia, masa lalunya yang sudah terlupakan dibentuk kembali oleh sejarawan atau sarjana asing. Setelah itu pada tahun 1920-an, George 
JURNAL NUANSA INFORMATIKA

Volume 15 Nomor 2, Juli 2021

Coedes menyebarkan penemuan pentingnya ini ke dalam bentuk koran yang kebetulan berbahasa Indonesia dan Belanda. George Coedes menyatakan bahwa referensi yang berasal dari Tiongkok yang berbunyi "Sanfo-ts-i” (Prof. Dr. Slamet Muljana, 2008)

Kerajaan Sriwijaya menjadi sebuah Icon kebesaran pulau Sumatera awal, dan kerajaan besar Lainnya yang berasal dari pulau Jawa termasuk Jawa Timpur yaitu Kerajaan Majapahit." Pada abad ke-20, kedua kerajaan tersebut menjadi rujukan oleh kaum nasionalis untuk menunjukkan bahwasannya Negara Indonesia adalah satu kesatuan negara sebelum kolonialisme Hindia Belanda."(Sholeh, 2018).

"Sebagai titik pusat pengajaran Agama Buddha Vajrayana di Sumatera, Kerajaan Sriwijaya menarik banyak peziarah dan para sarjana dari berbagai negara Asia. Termasuk I Tsing yaitu seorang pendeta dari Tongkok, yang melakukan ekspansi penelitian ke Sumatera. Dalam perjalanan belajarnya di Universitas Nalanda yaitu di negara India, pada tahun 671 sampai 695 , dan di abad ke11, Atisha merupakan sarjana Buddha yang berasal dari Benggala yang berperan dalam perkembangan agama Buddha Vajrayana di negara Tibet.(Sholeh, 2018).

\subsection{Pengertian RPG Maker MV}

Game engine yang digunakan untuk membuata RPG 2 dimensi salah satunya adalah RPG maker, dimana RPG marker ini memeiliki 7 versi yaitu Sim RPG Maker 95, RPG Maker 2000, RPG Maker 2003, RPG Maker XP, RPG Maker VX, RPG Maker VX Ace dan RPG Maker MV, dimana diversi terakhir versi yang lebih mudah karena berbasis GUI dan memilik tingkat kehalusan gambar lebih baik daripada versi seblumnya(Richard MH, Petrus Sokibi, 2018)

\subsection{Game}

p-ISSN : 1858-3911, e-ISSN : 2614-5405

https://journal.uniku.ac.id/index.php/ilkom

Game dikenal sebagai sarana hiburan yang baik untuk mengembangkan daya kreatifitas pemainnya. Aplikasi permainan atau game application merupakan salah satu implementasi dari ilmu dibidang komputer. Inti dari sebuah aplikasi permainan adalah mengembangkan kemampuan otak untuk mengatur strategi, kecepatan, dan ketepatan dalam mencapai tujuan akhir(Krisdiawan \& Ramdhany, 2018)

Jenis-jenis Game yang ada didunia :

1. Action Game

Action Game dikategorikan sebagai gameplay dengan model pertarungan. Action Adventure Game, berfokus pada eksplorasi dan biasanya mempunyai unsur item gathering, penyelesaian puzzle simpel, dan pertarungan (combat).

2. Adventure Game

Gameplay jenis ini adalah keharusan player memecahkan bermacam-macam puzzle melalui interaksi dengan orang lingkungan dalam game tersebut.

3. Role-Playing Game

Computer role-playing games atau CRPGs atau RPGs mempunyai gameplay di mana karakter milik player akan bertualang dengan skill combat atau cast spell Simulation Game

\subsection{Metode Penelitian Pengumpulan data}

Adapun metodologi yang penulis lakukan dalam penelitian ini adalah :

\section{Studi Kepustakaan}

Studi pustaka adalah mempelajari kajian ilmiah literatur tertulia dan teori-teori yang berhubungan dengan penilitian yang dilakukan

\section{Wawancara}

Wawancara ini dilakukan untuk mengetahui dan mensurvey model game RPG seperti apa yang sedang trend. 
JURNAL NUANSA INFORMATIKA

Volume 15 Nomor 2, Juli 2021

3. Dokumentasi dan Penyusunan Laporan

Untuk mendokumentasikan hasil dari penelitian baik dari sisi desain mau pun pada tahap pengembangan.

\section{Perancangan}

\subsection{Analisa Kebutuhan}

Analisis kebutuhan dilakukan dengan 2 pendekatan yaitu analisi kebutuhan fungsional dan analisis kebutuhan non fungsional, sebagai berikut :

\subsubsection{Analisa Kebutuhan Fungsional}

Game yang dibangun pada penelitian ini menggunakan konsep RPG yaitu sebuah jenis game yang biasanya memakai dasar cerita dan diubah menjadi sebuah permainan. Didalam game yang akan penulis buat player berperan sebagai seorang tokoh utama, dimana tokoh utama tersebut sebagai seorang ksatria kerajaan sriwijaya. Tujuan dari pemilihan sejarah diambil sebagai tema game adalah untuk mendorong penikmat game dalam hal ini muda untuk lebih tau mengenai sejarah lampau dari Indonesia terutama di sumatera.

\subsubsection{Analisa Kebutuhan non-fungsional}

Analisa kebutuhan non-fungsional merupakan analisa yang dibutuhkan untuk menentukan spesifikasi kebutuhan sistem. Baik itu perangkat lunak dan perangkat keras mulai dari tahap desain sampai dengan tahap implementasi

\subsection{Perancangan Sistem}

Perancangan adalah suatu bagian dari metodologi pengembangan suatu perangkat lunak yang dilakukan setelah tahapan analisis kebutuhan untuk memberikan gambaran secara terperinci. Perancangan sistem dapat berupa penggambaran,
p-ISSN : 1858-3911, e-ISSN : 2614-5405

https://journal.uniku.ac.id/index.php/ilkom

perancangan, dan pembuatan sketsa atau pengaturan dari beberapa elemen yang terpisah ke dalam satu kesatuan yang utuh dan berfungsi.

\subsubsection{Design Treatment}

Design treatment berisi informasi dasar mengenai aplikasi yang dikembangkan. Adapun design treatment pada game edukasi yang dibangun pada penelitian ini adalah sebagai berikut:

a. Judul Aplikasi : Game edukasi

Kerajaan Sriwijaya menggunakan RPG maker.

b. Definisi : Pengambilan judul

didasari dari sejarah Kerajaan Sriwijaya.

c. Genre : Education Game.

d. Player Interaction : Single Player.

e. Platform : Desktop.

f. Software digunakan : RPG MakerMV.

g. Target Player: Semua kalangan (10 sampai 25 tahun).

h. Basic goal : Pemain dapat menyelesaikan game dengan menjalankan misi utama dengan benar.

j. Basic Space : Memiliki latar sebuah kerjaan dan hutan.

k. Basic Mechanic : RPG.

1. Basic Rule : Player ditantang untuk menyelesaikan sebuah misi untuk menyelesaikan sebuah misi.

\subsubsection{Story Board}

Kerajaan Sriwijaya adalah salah satu kerajaan maritim yang kuat di wilayah pulau Sumatera dengan daerah kekuasaan membentang dari Thailand, Kamboja, Semenanjung Malaya, Jawa, Sumatera, Kalimantan, dan Sulawesi. prasasti Kedukan Bukit, pada tahun 682. Menunjukan bukti keberadaan sriwijaya yang berawal dari abad ke 7 di palembang

Kerajaan Sriwijaya menjadi icon kebesaran Sumatera awal, dan kerajaan 
JURNAL NUANSA INFORMATIKA

Volume 15 Nomor 2, Juli 2021

besar Nusantara di Jawa Timur selain Majapahit. Pada abad ke-20, kedua kerajaan tersebut menjadi rujukan oleh kaum nasionalis untuk menunjukkan bahwasanya Indonesia adalah satu kesatuan negara sebelum kolonialisme Belanda.

Raja Balaputradewa: diketahui dari catatan Prasasi Nalanda. Raja Balaputradewa menjabat sekitar abad ke-9, pada masa kekuasaannya, kerajaan Sriwijaya berkembang cepat menjadi kerajaan besar dan menjadi sebuah pusat agama Buddha di Asia Tenggara. Ia menjalin sebuah hubungan baik dengan kerajaan-kerajaan di India seperti Cola dan Nalanda. Balaputradewa merupakan keturunan dari dinasti Syailendra, yaitu putra dari Raja Samaratungga dengan Dewi Tara dari kerajaan Sriwijaya.

Prasasti Peninggalan Kerajaan Sriwijaya :

- Prasasti Kedukan Bukit

- Prasasti Karang Berahi

- Prasasti Talang ibo

- Prasasti Palas Pasemah

- Prasasti Telaga Batu

- Prasasti Kota Kapur

- Prasasti Leiden

- Prasasti Talang Tuwo

- Prasasti Ligor

- Prasasti Hujung Langit

Runtuhnya kerajaan Sriwijaya dikala itu ada serangan dari Rajendra Chola I yg merupakan seseorang dari dinasti Cholda di wilayah Koromande.

\subsubsection{Rule Game}

Pada masing masig level memiliki agenda atau misi utama. Berikut ini merupakan rincia penjelasan mengenai rules pada setiap harinya seperti terlihat pada table.

Tabel 1 Rule Game

\begin{tabular}{|l|l|}
\hline \multicolumn{2}{|c|}{ Level 1 } \\
\hline Misi Utama & $\begin{array}{l}\text { Training menjadi } \\
\text { sebuah prajurit biasa. }\end{array}$ \\
\hline
\end{tabular}

p-ISSN : 1858-3911, e-ISSN : 2614-5405

https://journal.uniku.ac.id/index.php/ilkom

\begin{tabular}{|l|l|}
\hline \multicolumn{2}{|c|}{ Level 2 } \\
\hline Misi Utama & $\begin{array}{l}\text { Mengalahkan musuh } \\
\text { dan mendapatkan } \\
\text { tambahan item. }\end{array}$ \\
\hline \multicolumn{3}{|c|}{ Level 3 } \\
\hline Misi Utama & $\begin{array}{l}\text { Mengalahkan musuh } \\
\text { dan mendapatkan } \\
\text { tambahan item baru. }\end{array}$ \\
\hline Misi Utama & $\begin{array}{l}\text { Mengalahkan musuh } \\
\text { dan mendapatkan } \\
\text { kenaikan pangkat } \\
\text { menjadi komandan } \\
\text { prajurit. }\end{array}$ \\
\hline Misi Utama & $\begin{array}{l}\text { Perang dengan } \\
\text { kerajaan lain dan } \\
\text { menjadi raja. }\end{array}$ \\
\hline
\end{tabular}

3.2.4 UML (Unified Modeling Language)

\section{Use Case Diagram}

Pada Gambar ditampilkan use case diagram dari game Kerajaan Sriwijaya. Menggambarkan fungsionalitas Ketika player memilih menu permainan baru, setelah itu player akan memainkan permainan level 1 sampai dengan level 5

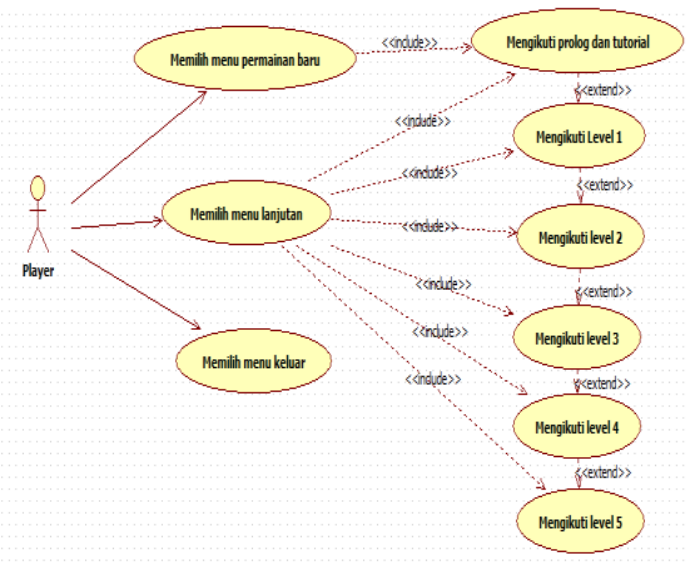

Gambar 1 Use Case Diagram

\section{Activity Diagram}

Menu Mulai pada game edukasi KErajaan Sriwijaya dapat dilihat pada Gambar berikut: 
JURNAL NUANSA INFORMATIKA

Volume 15 Nomor 2, Juli 2021

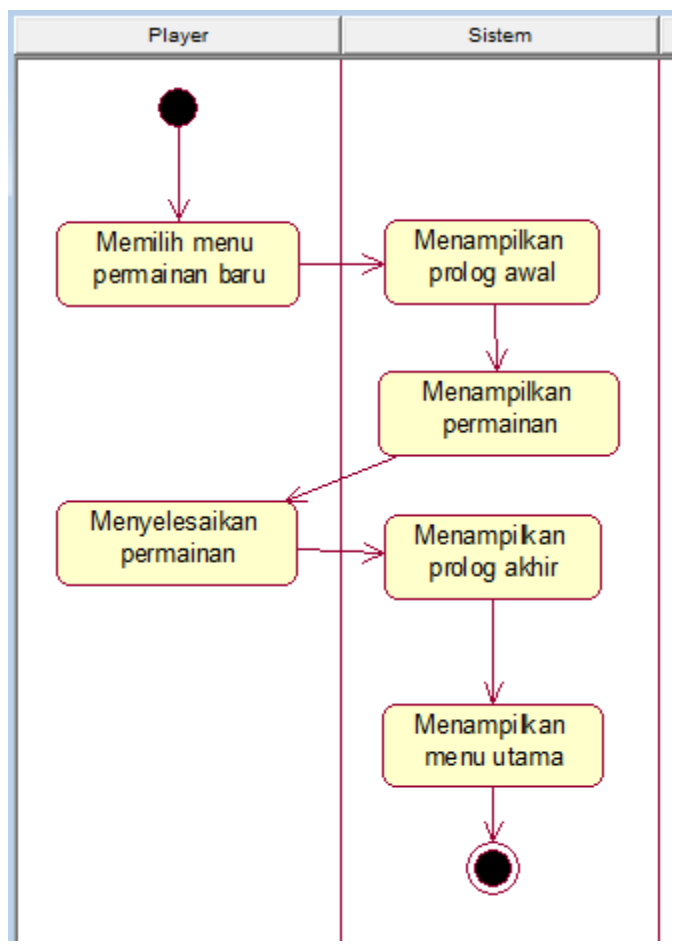

Gambar 2 Activity Diagaram menu

Activity diagram level 1 pada game edukasi Kerjaan Sriwijaya dapat dilihat pada Gambar berikut:

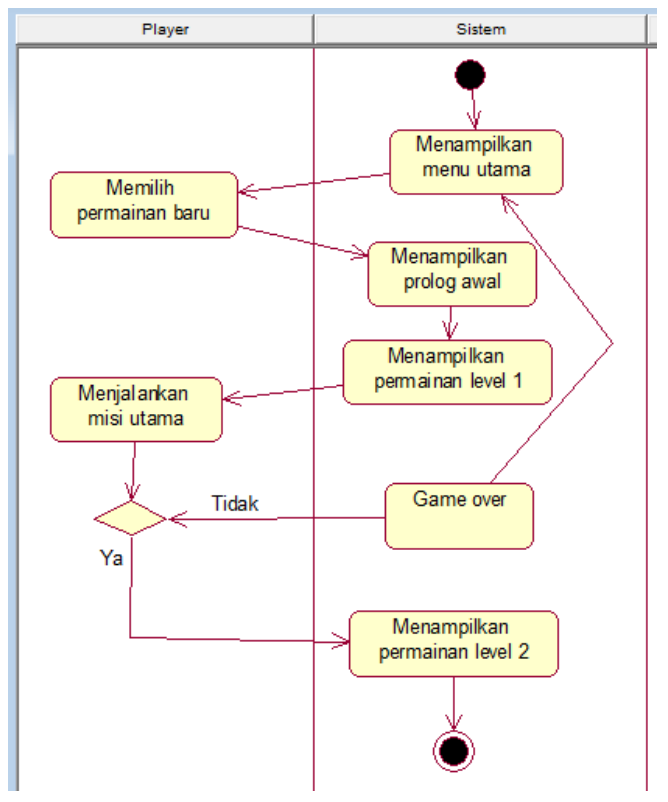

Gambar 3 Activity Diagram Level1

Keterangan gambar:

a. Sistem menampilkan menu utama.

b. Player memilih permainan baru.

c. Sistem menampilkan prolog awal.
p-ISSN : 1858-3911, e-ISSN : 2614-5405

https://journal.uniku.ac.id/index.php/ilkom

d. Setelah sistem menampilkan prolog awal, sistem akan menampilkan permainan level 1 dan ke level level berikutnya sampai dengan level 5 .

e. Setelah sistem menampilkan permainan level player harus menjalankan misi utama, jika tidak permainan akan berakhir (game over).

\subsubsection{Perancangan Prosedur}

Pada gambar ditampilkan flowchart dari Menu Utama game Kerajaan Sriwijaya. Ketika player membuka aplikasi game maka 26ymbol akan menampilkan tiga pilihan menu yang dapat dipilih oleh player. Menu tersebut adalah menu permain baru, menu lanjutan dan menu keluar.

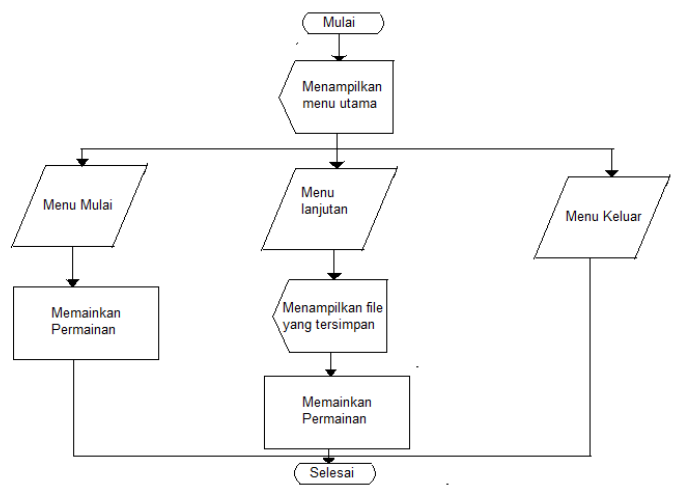

Gambar 4 Flowchart Menu

Perancangan Prosedur Menu permainan baru

Gambar merupakan aktivitas yang akan dilalui player ketika player memilih menu permainan baru pada menu utama sebelumnya. Prosedur Menu Permainan Baru pada game edukasi Kerajaan Sriwijaya dapat dilihat pada gambar. 
JURNAL NUANSA INFORMATIKA

Volume 15 Nomor 2, Juli 2021

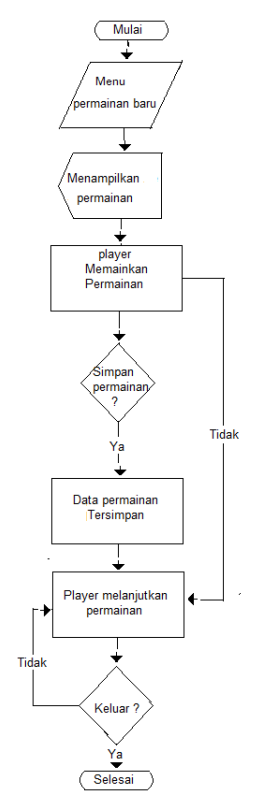

Gambar 5 Flowchart Permainan Baru

Perancangan Prosedural Level 1

Prosedur perancangan level 1 pada game Kerajaan Sriwijaya dapat dilihat pada gambar.

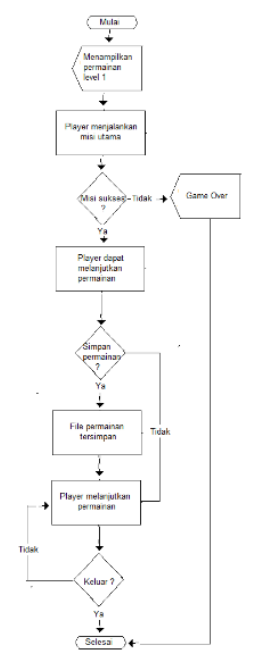

Gambar 6 Flowchart Permainan level 1

\section{Implementasi Dan Pengujian}

\subsection{Lingkup dan Batasan}

Lingkup dan Batasan untuk implementasi program ini adalah hanya mengisahkan Raja Balaputradewa yang menjabat jadi raja di abad ke-9 di kerajaan sriwijaya. Dari teknologi masih
p-ISSN : 1858-3911, e-ISSN : 2614-5405

https://journal.uniku.ac.id/index.php/ilkom

menggunakan 2D pixel dan Teknologi Grafis Menggunakan Game Role Playing (RPG). Game ini masih BETA Tester.

\subsection{Kebutuhan sumberdaya}

Hardware yang dibutuhkan yaitu :

a. CPU : core - duo @2.00Ghz (4 CPUs).

b. Memory RAM : $2 G B$.

c. Disk Space : (minimum) $500 \mathrm{MB}$.

d. Graphic Card: dengan VGA $512 \mathrm{MB}$.

e. Monitur VGA 14' dengan Resolusi 1366x 768 (32 bit) $(60 \mathrm{~Hz})$.

f. Keyboard.

Software yang di butuhkan.

a. Operating System.

\subsection{Implementasi Antarmuka}

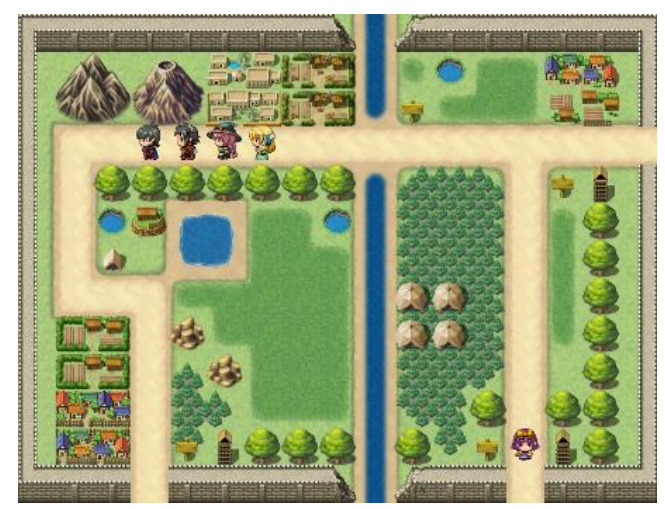

Gambar 7 Tampilan menu

Gambar di atas yaitu map awal yg terdiri dari kota 1 , kota 2 , kota 3 , hutan, pergunungan, dan kastil raja. Menjelaskan Mengenai alur cerita game dan nama nama tokoh utama seperti:

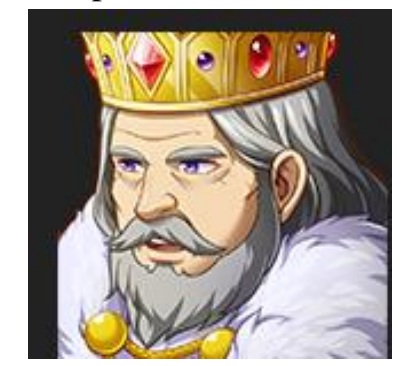

Gambar 9 Raja Balaputradewa 
Tokoh Raja di kerajaan Sriwijaya : Raja Balaputradewa salah satu Raja yang terkenal dari salah satu raja di kerajaan Sriwijaya dimana menjadi pusat agama hindu di asia.

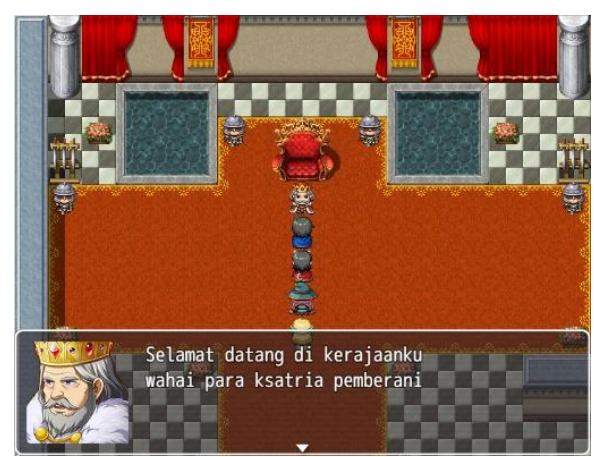

Gambar 10 Kastil Kerajaan

Didalam kastil , pemain akan bertemu raja dan akan mendapatkan misi.

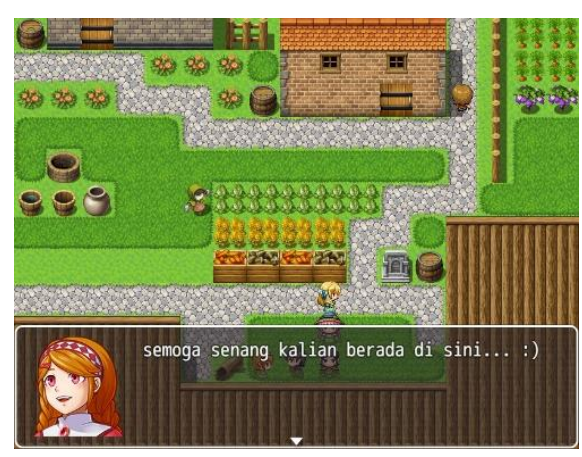

Gambar 11 Pemukiman Warga

Disini pemain bisa interaksi dengan warga warga yang ada di pemukan tersebut.

\section{Kesimpulan Dan Saran}

\subsection{Kesimpulan}

Kesimpulan yang diperoleh dari pembuatan game RPG berjudul "Kerajaan Sriwijaya" diantaranya adalah:

1. Dalam pembuatan game RPG untuk kalangan anak-anak sampai remaja dalam mengenal cerita kerajaan sriwijaya diperlukan kandungan konten game RPG
p-ISSN : 1858-3911, e-ISSN : 2614-5405

https://journal.uniku.ac.id/index.php/ilkom

yang dinamis dan realistis dengan konsep petualangan yang terjadi dimasa Kerajaan Sriwijaya.

2. Dengan adanya perkembangan jaman, pembuatan game ini diharapkan membantu masyarakat dalam mengenal sejarah Indonesia termasuk di pulau Sumatera. Dan perlu perkembangan lagi untuk bisa mengetahui manfaat dari penerapan permainan ini untuk penggunanya.

\subsection{Saran}

Game ini masih dapat dikembangkan sebagai berikut :

1. Permainan dapat lebih di perluas dengan menambahkan cerita ketika melawan musuh.

2. Daerah yang dijelajahi atau map dibuat lebih beragam dan menantang supaya pemain benar benar merasakan alur cerita yang dibuat dalam game.

3. Elemen elemen yang dipakai seperti peralatan, skill, dan musuh dibuat lebih variatif lagi.

\section{Daftar Pustaka}

Krisdiawan, R. A., \& Ramdhany, T. (2018). Implementasi Algoritma Fisher Yates Pada Games Edukasi Pengenalan Hewan Untuk Anak Sd Berbasis Mobile Android. Jurnal LPKIA.

Priyono, E., \& Buditjahjanto, I. G. P. A. (2012). Pengembangan Media Pembelajaran Edu-Game Adventure Pada Standar Kompetensi Menginstalasi Pc Di Smkn 1 Tuban. Jurnal Pendidikan Teknik Elektro, 1(1).

Prof. Dr. Slamet Muljana. (2008). Sriwijaya. LKiS.

Richard MH, Petrus Sokibi, D. M. (2018). Pembuatan Game Rpg " the Adventure of Sachi " Menggunakan Engine Rpg 
JURNAL NUANSA INFORMATIKA

Volume 15 Nomor 2, Juli 2021

Maker Mv. JURNAL DIGIT, 8(2), 185-196.

Sholeh, K. (2018). Analisis Prasasti Talang

Tuo Peninggalan Kerajaan Sriwijaya Sebagai Materi Ajar Sejarah Indonesia Di Sekolah Menengah Atas. Kalpataru: Jurnal Sejarah Dan Pembelajaran Sejarah, 2(2), 13. https://doi.org/10.31851/kalpataru.v2i 2.1592
p-ISSN : 1858-3911, e-ISSN : 2614-5405

https://journal.uniku.ac.id/index.php/ilkom

Wulandari, A. D. (2015). Game Edukatif Sejarah Komputer Menggunakan Role Playing Game (RPG) MAKER XP Sebagai Media Pembelajaran di SMP Negeri 2 Kalibawang. Unitersitas Negeri Yogyakarta, Unknown(Unknown), 4. http://www.dt.co.kr/contents.html?arti cle_no=2012071302010531749001 